\title{
Types of self-motions of planar Stewart Gough platforms
}

\author{
Georg Nawratil ${ }^{1}$ \\ ${ }^{1}$ Vienna University of Technology, Institute of Discrete Mathematics and Geometry, \\ Wiedner Hauptsrasse 8-10/104, 1040 Vienna, E-mail: nawratil@geometrie.tuwien.ac.at
}

With this talk, which is based on reference [1], we want to continue the series of contributions about selfmotions of Stewart Gough platforms given by KARGER [2,3] in the previous conferences on geometry theory and applications, held in Vorau 2007 and Plzen 2009.

We show that the self-motions of the general planar Stewart Gough platforms can be characterized in the complex extension of the Euclidean 3-space by the movement of three platform points in planes orthogonal to the planar base (3-point Darboux motion; cf. [4]) and a simultaneous sliding of three planes orthogonal to the planar platform through points of the base (3-plane Mannheim motion; cf. [4]). Based on this consideration, we can prove that all one-parametric self-motions of a general planar Stewart Gough platform can be classified into two types (type I DM and type II DM, where DM abbreviates Darboux Mannheim).

We also present a way on how the set of equations yielding a type II DM self-motion can be computed explicitly. Based on these equations, which are of great simplicity seen in the context of self-motions, we are also able to compute first results for this class of self-motions (cf. [5]). These results raise the hope of giving a complete classification of type II DM self-motions in the future, which would be an important step in solving the famous Borel Bricard problem [3, 6, 7, 8, 9]. The work towards this goal is in progress.

We close the talk by presenting a geometric interpretation of a large set of already known type II DM self-motions (cf. $[2,10]$ ), which also simplifies their computation considerably.

Acknowledgements This research was supported by Grant No. I 408-N13 of the Austrian Science Fund FWF within the project "Flexible polyhedra and frameworks in different spaces", an international cooperation between the Austrian Science Fund FWF and the Russian Foundation for Basic Research RFBR.

\section{References}

[1] Nawratil, G.: Types of self-motions of planar Stewart Gough platforms, under review.

[2] Karger, A.: Self-motions of Stewart-Gough platforms, Computer Aided Geometric Design, Special Issue: Classical Techniques for Applied Geometry (B. Jüttler, O. Röschel, E. Zagar eds.) 25 (9) 775-783 (2008).

[3] Karger, A.: Parallel manipulators and Borel-Bricard problem, Computer Aided Geometric Design, Special Issue: Advances in Applied Geometry (B. Jüttler, M. Lavicka, O. Röschel eds.) 27 (8) 669-680 (2010).

[4] Botтema, O., Roth, B.: Theoretical kinematics, Dover Publications (1990).

[5] Nawratil, G.: Basic result on type II DM self-motions of planar Stewart Gough platforms, In Proc. of 1st Workshop on Mechanisms, Transmissions and Applications, Timisoara October 6-8 2011, Romania, Springer (2011) to appear.

[6] Borel, E.: Mémoire sur les déplacements à trajectoires sphériques, Mém. présenteés par divers savants, Paris(2), 33, 1-128 (1908).

[7] Bricard, R.: Mémoire sur les déplacements à trajectoires sphériques, Journ. École Polyt.(2), 11, 1-96 (1906).

[8] Husty, M.: E. Borel's and R. Bricard's Papers on Displacements with Spherical Paths and their Relevance to Self-Motions of Parallel Manipulators, Int. Symp. on History of Machines and Mechanisms (M. Ceccarelli ed.), 163-172, Kluwer (2000).

[9] Vogler, H.: Bemerkungen zu einem Satz von W. Blaschke und zur Methode von Borel-Bricard, Grazer Mathematische Berichte 352 1-16 (2008).

[10] Karger, A.: New Self-Motions of Parallel Manipulators, Advances in Robot Kinematics: Analysis and Design (J. Lenarcic, P. Wenger eds.), 275-282, Springer (2008). 